\title{
Relation between weight retention after delivery and future pregnancy outcome
}

\author{
El Sayeed El Badawi, El Marsafawi A. \\ Osman NH. \\ a Department of Obstetrics and \\ Gynecology, Faculty of Medicine, \\ Alexandria University, Egypt.
}

\begin{abstract}
$\underline{\text { Abstract }}$
Introduction: The postpartum period may be a critical time for long-term weight gain and the development of maternal obesity. Excess weight gain during pregnancy and persistent weight retention 1 year postpartum are strong predictors of overweight a decade or more later, $14-20 \%$ of women retained $1-5 \mathrm{~kg}$ at 6 to 18 months postpartum. Women who did not return to their pre-pregnancy weight $6-18$ months postpartum are more likely to develop obesity in the long term. Aim of the work :was to study the relation between postpartum weight retention and future pregnancy outcomes as: preeclampsia, gestational diabetes, amount of weight gain during pregnancy, abortion rate, need for labor induction, cesarean section rates, occurrence of shoulder dystocia, fetal macrosomia, preterm labor, fetal death, accidental hemorrhage, congenital anomalies and abnormal presentations.
\end{abstract}

Results: In our study 152 women were recruited. Patients were divided into two groups according to history and examination in to: Group I: 76 women who retained more than $5 \mathrm{~kg}$ at $12-18$ months after the previous delivery and maintained till the next pregnancy. Group II (control group): 76 women who reached their pre-pregnancy weight at 12- 18 months postpartum or retained less than $5 \mathrm{~kg}$ from the previous pregnancy.According to our study there was statistical significant between retention of weight more than $5 \mathrm{~kg}$ with incidence of abortion, gestational diabetes, cesarean section and preeclampsia, where preeclampsia was more common with retention of weight above $8 \mathrm{~kg}$ in between pregnancy and there was no statistical signification with retention of weight with congenital anomalies, preterm labour, breech, induction of labour, deep vein thrombosis, intrauterine fetal death and postpartum hemorrhage.

Conclusion: Increase in the weight retention more than $5 \mathrm{~kg}$ showed increase in abortion, cesarean section, gestational diabetes mellitus and preeclampsia. There were no statistical difference between retention of weight and congenital anomalies, preterm labor, breech, deep vein thrombosis, intrauterine fetal death and postpartum hemorrhage.

Keywords: weight, retention, obesity, preeclampsia, diabetes.

\section{Introduction}

Obesity refers to an excess of body fat or adiposity. Body mass index (BMI) is widely recognized as a weight-for-height index that has a high correlation with adiposity.(1) Maternal obesity has significant health implications, contributing to increased morbidity and mortality for both mother and baby. ${ }^{(2)}$ According to the World Health Organization (WHO), overweight and obesity are defined as "abnormal or excessive fat accumulation that presents a risk to health." An individual with BMI from 18.5 to 24.9 is considering as normal person, a BMI from 25.0 to 29.9 is an overweight, a BMI from 30.0 to 34.9 is considering obese, and a BMI from 35.0 to 39.9 is considering as very obese. ${ }^{(3)}$ Obesity is associated with numerous chronic illnesses and a reduced quality of life and life expectancy. ${ }^{(4,5)}$ Pregnancy serves as a crucial point of intervention for the development of obesity 
during the life course. ${ }^{(6)}$ Women are 3 times more likely to develop obesity within 5 years following childbirth than women who have not been pregnant. (7) Excessive weight gain during pregnancy is the primary factor for postpartum weight retention. ${ }^{(8)}$ Other factors associated with an increased risk of greater weight retention are high pre-pregnancy body mass index (BMI), short breastfeeding period, primiparity, smoking cessation, high calorie intake, and low physical activity. The rate of gestational weight gain may be influenced by basal metabolic rate (BMR) at conception, which itself is highly dependent on pre-pregnancy body mass index (BMI). ${ }^{(9)}$ Changes in BMR of $20 \%$ to $30 \%$ have been reported at conception. ${ }^{(10)}$ Among underweight and normal weight women, BMR increases by $5 \%$ in the first trimester, $11 \%$ in the second trimester, and $24 \%$ in the third trimester. Among obese women, BMR increases by $7 \%, 16 \%$, and $38 \%$ in the first, second, and third trimesters. ${ }^{(10)}$ Antenatally, obesity increases the risk of miscarriage, gestational diabetes mellitus (GDM), gestational hypertension, thromboembolism, and preeclampsia. ${ }^{(11)}$ Obesity is associated with poor labour outcomes, with obese women less likely to go into labour spontaneously, more likely to have prolonged pregnancies and have their labour induced, and less likely to achieve a normal delivery, being at increased risk of caesarean section. ${ }^{(12.13)}$ Postnatally, obese women are less likely to breastfeed successfully, have a longer postnatal stay in hospital, and are at risk of postnatal infections. ${ }^{(14)}$ Obesity is also associated with a higher risk of adverse neonatal outcomes, including stillbirth, congenital anomalies, neonatal intensive care admission, and neonatal death. ${ }^{(11.12)}$

The aim of the work was to study the relation between postpartum weight retention and future pregnancy outcomes.

\section{Methods}

This study was a prospective randomized controlled study that had been performed over 152 women recruited from the antenatal care clinic in the Department of Obstetrics and Gynecology and private clinics, after approval of the ethics committee and fulfilling the criteria for inclusion in the study. A written informed consent had been taken from each patient.

Inclusion criteria:Female in reproductive age from 18 to 40 years, Multiparty, Singleton pregnancy and Interval between the previous and the present pregnancy less than or equals to 3 years. Exclusion criteria:Medical diseases such as pre-gestational diabetes mellitus and chronic hypertension, Smoking and History of any recurrent abnormal outcomes.
Patients had been divided into two groups: Group I: 76 women who retained more than $5 \mathrm{~kg}$ at 12-18 months after the previous delivery and maintained till the next pregnancy.Group II (control group): 76 women who reached their pre-pregnancy weight at 12- 18 months postpartum or retained less than $5 \mathrm{~kg}$ from the previous pregnancy and maintain it with annual visits as obtained from medical records.

All patients had been subjected to:The First antenatal care visit, early in first trimester:

Detailed history taking as regards :Demographic data as age, socioeconomic status, education, gravidity and parity, Maternal weight before previous pregnancy, Weight gain during previous pregnancy ,Maternal weight retention after the previous pregnancy at 1218 months postpartum, History of breast feeding and Maternal weight before present pregnancy.

And Clinical examination including general and gynecological examination including Body mass index [weight $(\mathrm{kg}) / \mathrm{ht}(\mathrm{m} 2)$ ].

Follow up to have the routine antenatal care: ${ }^{(15)}$ In the first 28 weeks of pregnancy, every 4 weeks. From 2836 weeks, every 2 weeks. Weekly after 36 weeks till delivery.

The patients were subjected to:Screening for gestational diabetes at 24-28 weeks of gestation by blood glucose level, O'sullivan test (It is considered positive when the glucose value is $140 \mathrm{mg} / \mathrm{dl}$ or higher). And confirmation by oral glucose tolerance test (it is consider positive when fasting blood glucose level is higher than $95 \mathrm{mg} / \mathrm{dL}$, One hour after drinking the glucose solution with blood glucose level is higher than $180 \mathrm{mg} / \mathrm{dL}$, Two hours blood glucose level is higher than $155 \mathrm{mg} / \mathrm{dL}$ and Three hours blood glucose level is higher than $140 \mathrm{mg} / \mathrm{dL}.)^{(16)}$

Screening for Preeclampsia by serum uric acid and uterine artery Doppler at 11-14 weeks and at 20-24 weeks of gestation to assess how the uterine artery flow waveform was abnormal by; ${ }^{(17)}$ Resistance index, pulsatility index, (systolic/diastolic ratio)

Ultrasound with special focus on: First trimester ultrasound assessment for anomalies. From 18 and 22 weeks for screening anomalies. Fetal weight and presentation at the third trimester.

Follow up of the patients during labor and postpartum till the end of puerperium.Outcome measures: Primary outcomes: where they were the first outcome appear during pregnancy and with high incidence: Gestational diabetes and Preeclampsia.Secondary outcomes: Amount of weight gain during pregnancy, Fetal 
macrosomia,Preterm birth, Fetal death, Accidental hemorrhage, Congenital anomalies, Abnormal presentations, Cesarean section, Shoulder dystocia, Deep vein thrombosis postpartum and Wound sepsis after delivery.

\section{$\underline{\text { Result }}$}

In group I (weight retention $>=5 \mathrm{~kg})(\mathrm{n}=76)$ the age ranged from 21 to 39 years with a mean of $29.24 \pm$ 3.558 , while in group II (weight retention $<5 \mathrm{~kg}$ ) $(n=76)$ it ranged from 22 to 37 years with a mean value $28.36 \pm 3.600$ years. There was no statistically significant difference in age between the two groups $(\mathrm{t}=1.397, \mathrm{p}=0.165)$. There was no statistically significant difference according to the socioeconomic state between the two groups $(\mathrm{t}=1.414, \mathrm{p}=0.156)$. Also the education and breast feeding showed no statistically significant difference in between the two groups. There was no significant statistical difference between two studied groups according to gravidity and recurrent abortions but there is significant different according to the parity ( $\mathrm{p}$ value were 0.003 ). There was significant statistical differences between the two studied groups in clinical outcomes including abortion in ( $\mathrm{p}$ value was 0.007$)$, pre-eclampsia and caesarian section rate ( $\mathrm{p}$ value were 0.008 and 0.026 successively). Although other clinical outcomes showed no significant statistical differences between the two studied groups.

Table 1: Comparison between the two studied groups according to clinical outcome in early and late pregnancy and postpartum

\begin{tabular}{|c|c|c|c|}
\hline $\begin{array}{l}\text { Clinical outcome in early } \\
\text { pregnancy }(<20 \text { weeks })\end{array}$ & Group $\mathrm{I}>=5 \mathrm{~kg}(\mathrm{n}=76)$ & Group II $<5 \mathrm{~kg}(\mathrm{n}=76)$ & Significance \\
\hline Abortion & $13(17.11 \%)$ & $4(5.36 \%)$ & $\begin{array}{l}X^{2}=4.147 \\
p=0.041 *\end{array}$ \\
\hline Multiple congenital anomalies & $2(2.63 \%)$ & $1(1.79 \%)$ & $\begin{array}{l}\mathrm{X}^{2} \text {, Yates }=0.000 \\
\mathrm{p}_{(\mathrm{Y})}=1.000 \mathrm{NS}\end{array}$ \\
\hline Cystic hygroma & $1(1.32 \%)$ & $0(0.00 \%)$ & $\begin{array}{l}\mathrm{X}^{2}(\text { Yates })=0.000 \\
\mathrm{p}_{(\mathrm{Y})}=1.000 \mathrm{NS}\end{array}$ \\
\hline Trisomy 18 & $1(1.32 \%)$ & $0(0.00 \%)$ & $\begin{array}{l}\mathrm{X}^{2}(\text { Yates })=0.000 \\
\mathrm{p}(\mathrm{Y})=1.000 \mathrm{NS}\end{array}$ \\
\hline \multicolumn{4}{|l|}{$\begin{array}{l}\text { Clinical outcome in late } \\
\text { pregnancy }(>20 \text { weeks })\end{array}$} \\
\hline PET & $12(15.79 \%)$ & $3(3.57 \%)$ & $\begin{array}{l}X^{2}=5.077 \\
p=0.024 *\end{array}$ \\
\hline CS & $9(16.36 \%)$ & $2(3.64 \%)$ & $\begin{array}{l}\mathrm{X}^{2}=4.949 \\
\mathrm{p}=0.026^{*}\end{array}$ \\
\hline GDM & $4(5.26 \%)$ & $3(3.57 \%)$ & $\begin{array}{l}\mathrm{X}^{2}(\text { Yates })=0.001 \\
\mathrm{p}(\mathrm{Y})=0.969 \mathrm{NS}\end{array}$ \\
\hline Macrosomic baby & $5(6.58 \%)$ & $0(0.00 \%)$ & $\begin{array}{l}\mathrm{X}^{2}(\text { Yates })=2.237 \\
\mathrm{p}(\mathrm{Y})=0.135 \mathrm{NS}\end{array}$ \\
\hline IUFD & $2(2.63 \%)$ & $3(3.57 \%)$ & $\begin{array}{l}\mathrm{X}^{2}(\text { Yates })=0.000 \\
\mathrm{p}(\mathrm{Y})=1.000 \mathrm{NS}\end{array}$ \\
\hline Breech & $2(2.63 \%)$ & $3(3.57 \%)$ & $\begin{array}{l}\left.\mathrm{X}^{2} \text { (Yates }\right)=0.000 \\
\mathrm{p}(\mathrm{Y})=1.000 \mathrm{NS}\end{array}$ \\
\hline Induction of labour & $0(0.00 \%)$ & $3(3.57 \%)$ & $\begin{array}{l}\left.\mathrm{X}^{2} \text { (Yates }\right)=0.882 \\
\mathrm{p}(\mathrm{Y})=0.348 \mathrm{NS}\end{array}$ \\
\hline Transverse lie & $2(2.63 \%)$ & $0(0.00 \%)$ & $\begin{array}{l}\mathrm{X}^{2}(\text { Yates })=0.252 \\
\mathrm{p}(\mathrm{Y})=0.615 \mathrm{NS}\end{array}$ \\
\hline Preterm labour pain & $1(1.32 \%)$ & $0(0.00 \%)$ & $\begin{array}{l}\mathrm{X}^{2}(\text { Yates })=0.000 \\
\mathrm{p}(\mathrm{Y})=1.000 \mathrm{NS}\end{array}$ \\
\hline
\end{tabular}




\begin{tabular}{|l|c|c|c|}
\hline DVT & $1(1.32 \%)$ & $0(0.00 \%)$ & $\begin{array}{l}\mathrm{X}^{2}(\text { Yates })=0.000 \\
\mathrm{p}(\mathrm{Y})=1.000 \mathrm{NS}\end{array}$ \\
\hline Twin & $1(1.32 \%)$ & $0(0.00 \%)$ & $\begin{array}{l}\mathrm{X}^{2}(\text { Yates })=0.000 \\
\mathrm{p}(\mathrm{Y})=1.000 \mathrm{NS}\end{array}$ \\
\hline Postpartum outcome & $2(2.63 \%)$ & $0(0.00 \%)$ & $\begin{array}{l}\mathrm{X}^{2}(\text { Yates })=0.252 \\
\mathrm{p}(\mathrm{Y})=0.615 \mathrm{NS}\end{array}$ \\
\hline $\begin{array}{l}\text { Primary Postpartum } \\
\text { hemorrhage }\end{array}$ & & & \\
\hline
\end{tabular}

Outcome is not mutually exclusive

NS: Non significant $(\mathrm{p}>0.05)$

*Significant n: Number

$\chi 2$ : Chi square test

$\mathrm{p}$ : $\mathrm{p}$ value for comparing between the two studied group

GDM: Gestational Diabetes Mellitus

IUFD: intrauterine fetal death

Y: Continuity correction (Yate's) for Chi-Square test

DVT: deep vein thrombosis

The retention of weight in between pregnancy with no outcome in next pregnancy was ranged from 0 to $14 \mathrm{Kg}$ with a mean of $4.3871 \pm 3.357 \mathrm{Kg}$, while the retention of weight in between pregnancy with pregnancy outcome in next pregnancy was ranged from 0 to $24 \mathrm{Kg}$ with a mean value $7.664 \pm 4.481 \mathrm{Kg}$. there was statistically significant value for weight retention in between pregnancy and outcomes with next pregnancy.

Table 2: the relation between retention of weight and outcome.

\begin{tabular}{|l|c|c|}
\hline \multicolumn{1}{|c|}{$\begin{array}{c}\text { Weight } \\
\text { retention }(\mathrm{kg})\end{array}$} & $\begin{array}{c}\text { negative } \\
\text { outcome }\end{array}$ & $\begin{array}{c}\text { positive } \\
\text { outcomes }\end{array}$ \\
\hline Number & 82 & 70 \\
\hline Minimum & $0 \mathrm{~kg}$ & $0 \mathrm{~kg}$ \\
\hline Maximum & $14 \mathrm{~kg}$ & $24 \mathrm{~kg}$ \\
\hline Mean & 4.3871 & 7.6643 \\
\hline S.D. & 3.35767 & 4.48162 \\
\hline $\begin{array}{l}\text { Independent samples t-test } \\
\text { p value }\end{array}$ & $\begin{array}{l}\mathrm{t}=4.705 \\
\mathrm{p}=0.000^{*}\end{array}$ \\
\hline $\begin{array}{l}\text { Paired samples t-test } \\
\text { p value }\end{array}$ & $\begin{array}{l}\mathrm{t}=10.224 \\
\mathrm{p}=0.000^{*}\end{array}$ & $\begin{array}{l}\mathrm{t}=10.284 \\
\mathrm{p}=0.000^{*}\end{array}$ \\
\hline
\end{tabular}

*Significant

S.D: Standard deviation.

p: $p$ value for comparing between the two studied group

t: Student t-test

Our study showed that there were 10 cases with retention of weight $>11 \mathrm{~kg}$ with outcomes as abortion, pre-eclampisa, gestational diabetes mellitus and macrocosmic baby. There were 2 cases with retention of weight $>20 \mathrm{~kg}$ one of them was missed abortion and the other was gestational diabetes mellitus. There was a case of DVT presented with retention weight of $9 \mathrm{~kg}$. And no cases with accidental hemorrhage, shoulder dystocia or wound sepsis. Also the result showed no statistical different between weights before, during or after the previous pregnancy and next pregnancy outcome.

\section{Discussion}

Weight gain during pregnancy and the effect on subsequent weight gain are causes of a permanent increase in weight. More than $60 \%$ of previous gravid become overweight with their subsequent pregnancies.

(3) Obesity is associated with numerous chronic illnesses and a reduced quality of life and life expectancy. ${ }^{(4.5)}$ Pregnancy serves as a crucial point of intervention for the development of obesity during the life course. ${ }^{(6)}$ Women are 3 times more likely to develop obesity within 5 years following childbirth than women who have not been pregnant. ${ }^{(7)}$ This may put women at risk for being obese during subsequent pregnancies, thereby increasing the risk for adverse outcomes. ${ }^{(7)}$

The aim of the study was to evaluate the relation between retention of weight from previous pregnancy and next pregnancy outcomes.

In our study 152 women were recruited from multiple private antenatal care clinics. Patients were divided into two groups according to history and examination in to: Group I: 76 women who retained more than $5 \mathrm{~kg}$ at 12 18 months after the previous delivery and maintained till the next pregnancy. Group II (control group): 76 women who reached their pre-pregnancy weight at 1218 months postpartum or retained less than $5 \mathrm{~kg}$ from the previous pregnancy.

Our study showed there was increase in incidence of outcomes as abortion $(17.1 \%)$, pre-eclampsia $(15.79 \%)$ and caesarean section $(16.3 \%)$ in women who retained more than $5 \mathrm{~kg}$ from previous pregnancy unlike women that didn't retained or retained less than $5 \mathrm{~kg}$ from previous pregnancy, they were $(5.3 \%, 3.57 \%$ and $3.64 \%$ respectively). While the other outcomes, there were 
no significant difference in incidence between the two groups of study.

Our study showed there was no statistically significant difference in age between the two groups while in $\mathrm{Yi} \mathrm{Li}$ et al. ${ }^{(18)}$ showed that maternal age is independent risk factor for weight gain and pregnancy outcomes in huge sample size $(>100000$ cases) with different age group (15-45 years) which in contrast with our study. This may be due to large sample size in comparison to ours. Also, they were be able to classify this large sample size into different age groups which was not possible in our study. Eduardo V. et al. (19) showed that the risk of adverse outcomes increased linearly with weight gain between pregnancies, the risks of preeclampsia, gestational hypertension, gestational diabetes, and large-forgestational-age birth started to rise at weight gains more than $4-5 \mathrm{Kg}$ and continued to increase progressively thereafter that was agree with our study where the more retention of weight in between pregnancy, the more outcomes had been showed in the next pregnancy.

Nohr et al reported an increased risk for Gestation Diabetes Mellitus (GDM) in overweight women and obese women to 5 times than that in normal weight. ${ }^{(20,21)}$ Chu et al included 20 studies in a meta-analysis and found that the risk of developing GDM was increased 3.6 times in obese compared with normal-weight women, and increased 8.6 times in severely obese in compared with normal weight women. But Our study show no significant different in between two group for retention of weight in between pregnancy and had gestation diabetes mellitus. This is also can be due to the difference in the type of the study and the sample size.

Preeclampsia complicates $3-5 \%$ of all pregnancies and obesity is a consistent risk factor for preeclampsia, approximately three times higher than in normal-weight women. ${ }^{(22)}$ In an overview of 13 cohort studies including nearly 1.4 million women, O'Brien et al observed a consistent and linear rise in the risk for preeclampsia with increasing pre-pregnancy weight retention. ${ }^{(23)}$ The risk of preeclampsia doubled with each 5-7-point increase in BMI. ${ }^{(24)}$ Which agree with our study that showed increasing in incidence of pre-eclampsia with retention of weight in between pregnancies more than $8 \mathrm{~kg}$.

The risk of cesarean delivery and associated morbidities are increased in obese women. In an American population the figures were $21.3 \%$ (BMI $20-25$ ), $32.6 \%$ in obese (BMI $30-35$ ), 36.9\% in very obese (BMI 35-40), and $45.2 \%$ in extremely obese women (BMI more than 40). ${ }^{(25)}$ A meta-analysis performed by $\mathrm{Chu}$ et al estimated that the risk of having a cesarean delivery was approximately two and three times higher among obese and severely obese women, respectively, compared with women of normal weight. In addition, the majority of these deliveries were performed during the first stage of labor and based on indications of dystocia and fetal distress. (26) Which is agree with our study where increase the weight retention lead to increase cesarean Section rate in the next pregnancy and showed statistical significant different in between the two groups of study. In a recent review including 11 papers, cesarean delivery risk was increased by $50 \%$ in overweight women and was more than doubled for obese women compared with women with normal BMI. ${ }^{(27)}$ Obese women undergoing cesarean delivery experienced more complications, including blood loss more than $1,000 \mathrm{~mL}$, increased operative time, increased postoperative wound infection, and endometritis. ${ }^{(28)}$

In a recent meta-analysis it was concluded that overweight, obese, and morbidly obese pregnant women had significantly increased risk of hemorrhage compared with normal weight women. ${ }^{(2)}$ these were in contrast with our study that there was no significant different between the two groups in postpartum hemorrhage.

Maternal obesity was a well-known risk factor for fetal macrosomia. Owens et al found that the percentage of macrosomic neonates (more than 4,000 g) to increase from $15.5 \%$ to $21.4 \%$ to $27.8 \%$ in normal weight, overweight, and obese women, respectively. (30) Maternal diabetes was also a well-known risk factor for macrosomia. Ehrenberg et al examined the relative contribution of obesity and diabetes for the prevalence of large for gestational age LGA neonates (more than 90 percentile) at birth, and found that pre-gestational diabetes had a greater effect on the frequency of LGA than did maternal obesity. ${ }^{(31)}$ While our study showed no different between the two groups of study in large gestational weight neonate. In our study there wasn't any relation between weight retention in between pregnancy and should dystocia, which in a Swedish study increased from $0.1 \%$ to $0.3 \%$ in the normal weight mothers compared with the obese mothers. ${ }^{(31)}$ Usha Kiran et al reported an increase from $0.5 \%$ in overweight women to $1.5 \%$ in obese women. ${ }^{(32)}$

In a study of 24,505 singleton pregnancies, the overall rate of stillbirth was 4.6 per 1,000 deliveries. Compared with women of normal weight, the relative risk of stillbirth in obese women was nearly tripled. ${ }^{(33)}$ In another study of 54,505 pregnancies, the risk of stillbirth was 2.8 per 1,000 . The risk for stillbirth among obese women was significantly higher as gestational age advanced (weeks 40 and more). ${ }^{(34)}$ Furthermore, obesity was associated with a five-fold increase in risk of stillbirth with placental dysfunction. While in our 
study there was no significant different between two study groups according to preterm labour, intrauterine fetal death (IUFD) and in congenital anomalies but it showed statistical significant different between the two groups with abortion which was increased with retention of weight.

\section{Conclusion}

Increase in the weight retention more than $5 \mathrm{~kg}$ showed increase in abortion, cesarean section, gestational diabetes mellitus and preeclampsia. There were no statistical difference between retention of weight and congenital anomalies, preterm labor, breech, deep vein thrombosis, intrauterine fetal death and postpartum hemorrhage. We should tell women about the importance of getting normal BMI after delivery and before next pregnancy during their postpartum and pre-pregnancy counseling visits. We recommend studying the association of the inter-pregnancy retention of weight with gestation diabetes and gestational hypertensive disorders on larger sample size.We recommend studying the mechanism of weight retention in between pregnancy and the long term effects later in a woman's life.

\section{$\underline{\text { References }}$}

1. Guelinckx I, Devlieger R, Beckers K. Maternal obesity: pregnancy complications, gestational weight gain and nutrition. Obes Rev 2008; 9(2): 14050 .

2. Centre for Maternal and Child Enquiries (CMACE). Saving Mothers' Lives: reviewing maternal deaths to make motherhood safer: 2006-2008. The Eighth Report on Confidential Enquiries into Maternal Deaths in the United Kingdom. BJOG 2011;118(Suppl. 1):1-203.

3. DeVader SR, Neeley H, Myles T. Evaluation of gestational weight gain guidelines for women with normal pre-pregnancy body mass index. Obstetrics \& Gynecology; T. L 2007; 110:745-51.

4. Cameron AJ, Magliano DJ, Dunstan DW, et al. A bidirectional relationship between obesity and healthrelated quality of life: evidence from the longitudinal AusDiab study. Int J Obes. 2012;36(2):295-303.

5. Vucenik I, Stains JP, et al. Obesity and cancer risk: evidence, mechanisms, and recommendations. Ann New York Acad Sci. 2012;1271(1):37-43.

6. Mamun AA, Kinarivala M, O'Callaghan MJ, et al. Associations of excess weight gain during pregnancy with long-term maternal overweight and obesity: evidence from 21 y postpartum follow-up.
Am J Clin Nutr. 2010;91(5):1336-41.

7. Davis EM, Zyzanski SJ, Olson CM, et al. Racial, ethnic, and socioeconomic differences in the incidence of obesity related to childbirth. Am J Public Health. 2009;99:294-9.

8. Ashley-Martin J, Woolcott C. Gestational weight gain and postpartum weight retention in a cohort of Nova Scotian women. Matern Child Health J. 2014;18(8):1927-35.

9. King JC. Maternal obesity, metabolism, and pregnancy outcomes. Annu Rev Nutr. 2006;26:27191.

10. Allen LH. Weight gain. Encyclopedia of Human Nutrition. 2013;4:99-103.

11. Dodd JM, Grivell RM, Nguyen A, et al. Maternal and perinatal health outcomes by body mass index category. Aust N Z J Obstet Gynaecol 2011;51:13640.

12. Kerrigan AM, Kingdon C, et al. Maternal obesity and pregnancy: a retrospective study. Midwifery 2010;26:138-46.

13. Schrauwers C, Dekker G, et al. Maternal and perinatal outcome in obese pregnant patients. The Journal of Maternal-Fetal and Neonatal Medicine 2009;22:218-26.

14. Baker J, Michaelsen KF, Sorensen TIA, et al. High prepregnant body mass index is associated with early termination of full and any breastfeeding in Danish women. Am J Clin Nutr 2007;86:404-11.

15. Cristina V, Moira AM, David J, et al. Antenatal care for twin and triplet pregnancies: summary of NICE guidance. BMJ 2011; 343:5714.

16. Landon MB, Spong CY, Thom E, et al. A multicenter, randomized trial of treatment for mild gestational diabetes. N Engl J Med 2009; 361:1339-48.

17. Angeli F, Angeli E, Reboldi G, et al. Hypertensive disorders during pregnancy: clinical applicability of risk prediction models. J Hypertens 2011; 29:23;20.

18. Yi Li, Qi-Fei Liu, Dan Zhang et al. Weight Gain in Pregnancy, Maternal Age and Gestational Age in Relation to Fetal Macrosomia. Clin Nutr Res. 2015; 4(2): 104-9.

19. Eduardo V., S Cnattingius, et al. Inter-pregnancy weight change and risk of adverse pregnancy outcomes: a population-based study. Lancet 2006; 368: 1164-70.

20. Nohr EA, Vaeth M, Baker JL, et al. Combined associations of pre-pregnancy body mass index 
and gestational weight gain with the outcome of pregnancy. Am J Clin Nutr 2008;87:1750 -9.

21. Nohr EA, Timpson NJ, Andersen CS, et al. Severe obesity in young women and reproductive health: the Danish National Birth Cohort. PLoS One 2009;4: 8444.

22. Chu SY, Callaghan WM, Kim SY, et al. Maternal obesity and risk of gestational diabetes mellitus. Diabetes Care 2007;30:2070 - 6.

23. O'Brien TE, Ray JG, Chan WS, et al. Maternal body mass index and the risk of preeclampsia: a systematic overview. Epidemiology 2003;14:368 -74.

24. WalshSW,etal.Obesity:arisk factorforpreeclampsia. Trends Endocrinol Metab 2007;18:365-70.

25. Chu SY, Bachman DJ, Callaghan WM, et al. Association between obesity during pregnancy and increased use of health care. N Engl J Med 2008;358:1444-53.

26. Chu SY, Kim SY, Schmid CH, et al. Maternal obesity and risk of cesarean delivery: a meta-analysis. Obes Rev 2007;8:385-94.

27. Brown K, Apuzzio J, Weiss G, et al. Maternal obesity and associated reproductive consequences. Womens Health (Lond Engl) 2010;6:197-203.
28. Poobalan AS, Aucott LS, Gurung T, et al. Obesity as an independent risk factor for elective and emergency caesarean delivery in nulliparous women-systematic review and meta-analysis of cohort studies. Obes Rev 2009; 10: 28-35.

29. Heslehurst N, Simpson H, Ells LJ, Rankin J, Wilkinson J, Lang R, et al. The impact of maternal BMI status on pregnancy outcomes with immediate short-term obstetric resource implications: a metaanalysis. Obes Rev 2008;9:635-83.

30. Owens LA, O'Sullivan EP, Kirwan B, et al. The impact of obesity on pregnancy outcome in glucose-tolerant women. Diabetes Care 2010;33:577-9.

31. Ehrenberg HM, Mercer BM, Catalano PM. The influence of obesity and diabetes on the prevalence of macrosomia. Am J Obstet Gynecol 2004;191:964 - 8 .

32. Usha Kiran TS, Hemmadi S, Bethel J, Evans J. Outcome of pregnancy in a woman with an increased body mass index. BJOG 2005;112:768 -72.

33. Kristensen J, Vestergaard M, Wisborg K, Kesmodel $\mathrm{U}$, Secher NJ. Pre-pregnancy weight and the risk of stillbirth and neonatal death. BJOG 2005;112:403-8.

34. Nohr EA, Bech BH, Davies MJ, Frydenberg M, Henriksen TB, Olsen J. Prepregnancy obesity and fetal death: a study within the Danish National Birth Cohort. Obstet Gynecol 2005; 106:250 -9 